\title{
Social Behavior and Autism Traits in a Sex Chromosomal Disorder: Klinefelter (47XXY) Syndrome
}

\author{
Sophie van Rijn · Hanna Swaab · André Aleman · \\ René S. Kahn
}

Published online: 7 March 2008

(C) The Author(s) 2008

\begin{abstract}
Although Klinefelter syndrome (47,XXY) has been associated with psychosocial difficulties, knowledge of the social behavioral phenotype is limited. We examined specific social abilities and autism traits in Klinefelter syndrome. Scores of $31 \mathrm{XXY}$ men on the Scale for Interpersonal Behavior and the Autism Spectrum Questionnaire were compared to 24 and 20 control men respectively. XXY men reported increased distress during social interactions and less engagement in specific social behaviors. In the XXY group, levels of autism traits were significantly higher across all dimensions of the autism phenotype. These findings call for a clinical investigation of vulnerability to autism in Klinefelter syndrome. Klinefelter syndrome might serve as a model for studying a role of the $\mathrm{X}$ chromosome in social behavioral dysfunction and autism-like behavior.
\end{abstract}

Keywords Klinefelter syndrome - Autism traits . $\mathrm{X}$ chromosome $\cdot$ Social behavior $\cdot \mathrm{XXY}$

S. van Rijn

Department of Experimental Psychology, Helmholtz Instituut,

Universiteit Utrecht, Utrecht, The Netherlands

S. van Rijn · R. S. Kahn

Department of Psychiatry, Rudolf Magnus Institute of Neuroscience, University Medical Center Utrecht,

Utrecht, The Netherlands

S. van Rijn $(\bowtie) \cdot$ H. Swaab

Department of Clinical Child and Adolescent Studies, Leiden University, Wassenaarseweg 52, Postbus 9555, 2300 RB Leiden, The Netherlands

e-mail: srijn@fsw.leidenuniv.nl

A. Aleman

BCN NeuroImaging Center, University of Groningen, Groningen, The Netherlands
Klinefelter syndrome affects approximately 1 in 700 men and is the most commom sex chromosomal disorder. Men with this syndrome have an extra $\mathrm{X}$ chromosome, giving rise to the XXY chromosomal pattern. This sex chromosomal aneuploidy results in a variety of phenotypes including hypogonadism, androgen deficiency and infertility (Lanfranco et al. 2004). Cognitive and behavioral dysfunctions in Klinefelter syndrome have generally been under-appreciated relative to endocrinological and physical features. However, there is an awareness of behavioral and cognitive abnormalities (Boone et al. 2001; Geschwind et al. 2000). Although there is a general impression that men or boys with Klinefelter syndrome often struggle with social situations (for example at school or at work), knowledge of the social behavioral phenotype of Klinefelter syndrome is limited. Previous studies have predominantly assessed global functioning (for example academic achievement, occupation or marital status) rather specific social abilities. Some studies have specifically focused on social adjustment in adolescents and men with Klinefelter syndrome, but these studies have primarily collected categorical data (for example, someone can be either sociable, passive or shy) or the studies included small sample sizes or lacked control data from individuals from the general population. These studies suggest that individuals with Klinefelter syndrome are at risk for psychosocial and emotional problems such as social withdrawal, social anxiety, shyness, impulsivity and inappropriate social behavior (Bender et al. 1999; Geschwind et al. 2000; Geschwind and Dykens 2004; Ratcliffe 1999; Simm and Zacharin 2006). In early adulthood a significant portion of the XXY men report having few or no friends, poor relations with siblings and parents, little energy and initiative, and few or no sparetime interests (Nielsen et al. 1980). 
Although speculative, difficulties in coping with the social environment may be indicative of an increased vulnerability for autistic traits in boys and men Klinefelter syndrome. Tentative support for this hypothesis comes from recent case studies of individuals with Klinefelter syndrome diagnosed with an autism spectrum disorder (Jha et al. 2007; Merhar and Manning-Courtney 2007). Also, population based studies investigating genetic disorders in individuals with autism have commented on the co-occurance of autism and the XXY pattern (Kielinen et al. 2004; Konstantareas and Homatidis 1999). However, to our knowledge, there has been no study of autism features in a large sample individuals with Klinefelter syndrome.

The aim of our study was to investigate specific social abilities in a large sample of adult men with Klinefelter syndrome and assess whether Klinefelter syndrome may be associated with increased levels of autistic traits. In an attempt to improve our understanding of the social behavioral phenotype of Klinefelter syndrome, our study included a quantitative measure of the degree to which XXY men participate in specific social behaviors and at the same time the degree to which XXY men are distressed during these social situations as compared to men from the general population. Importantly, this measure allows a quantification of social capacities that are normally distributed in the general population. Also, it has shown to be sensitive to the effects of social skills training, indicating that it is a sensitive measure of individual differences in social behavior.

To explore the extend to which social disabilities reflect increased levels of features that belong to the autism phenotype, we included a quantitative measure of autism traits. Rather than using a dichotomous, categorical diagnosis of autism that would result in an all-or-none score, we used a dimensional measure of autistic personality traits which are distributed along a continuum in the general population (Baron-Cohen et al. 2001; Constantino and Todd 2003; Spiker et al. 2002). By quantifying the degree of autistic traits we were able to sensitively measure vulnerability for autistic features in men with Klinefelter syndrome. Cut-off scores for Asperger syndrome and high functioning autism as provided by Woodbury-Smith et al. (2005) and BaronCohen et al. (2001) allowed us to assess the proportion of XXY men with autism features in a clinical range.

\section{Methods}

\section{Participants}

We included 31 men with Klinefelter syndrome (mean age 41.3, SD 10.0) with help from the Dutch Klinefelter Association. By means of advertisements we invited men to participate in a study on behavior. Participants were not selected for psychological or behavioral abnormalities. Diagnosis of Klinefelter syndrome was confirmed by karyotyping, using standard procedures. Twenty-four men were treated with testosterone supplements, with a mean age of treatment onset of 26.9 years (SD 7.6). Highest level of education in the XXY group was secondary school in $29 \%$, vocational education in $50 \%$ and higher education in $21 \%$. Data on intellectual abilities as measured with the WAIS-III were available in our database for the XXY men (intellectual abilities were measured within one year of the present study). Mean general intelligence in the XXY group was 93.5 (SD 11.1), with a score of 92.6 (SD 12.0) for verbal intelligence and 93.6 (SD 18.6) for performance intelligence.

Because the present study was part of a larger study in which several control groups have been included, the present research questions were tested using two different control groups. We compared autism traits in XXY men with 20 men from the general population (control group I), who were recruited using advertisments in local newspapers. Mean age in this group was 39.2 years (SD 13.1). Social behavior in XXY men was compared with 24 men from the general population (control group II). Mean age in this group was 35.7 (SD 8.5). There were no significant differences in age between the three groups, as indicated by an ANOVA as well as post-hoc tests $(F(2,72)=1.8$, $p=0.16)$. None of the control subjects had a history of psychiatric illness as confirmed with the Mini International Neuropsychiatric Interview plus (MINI) (Sheehan et al. 1998). Highest level of education in the control groups (collapsed) was secondary school in $29 \%$, vocational education in $42 \%$ and higher education in $29 \%$.

The study was approved by the local ethics committee and written informed consent was obtained according to the declaration of Helsinki.

Intellectual Ability

\section{Raven's Advanced Progressive Matrices (short form)}

This test is commonly accepted as a measure of general intelligence and has been shown to correlate with a number of other standardized intelligence tests (Lezak 1995; Raven et al. 1993). Subjects are shown 12 pictures of matrices (i.e., related patterns), each of which is a figural design with a part removed. The subject must choose the correct missing part from eight options.

\section{National Adult Reading Test (NART)}

The Dutch translation of the NART (Nelson 1982; Schmand et al. 1991) provides an estimate of verbal IQ and is 
based on the high correlation between reading ability, specifically of irregular words, with intelligence in the normal population. Subjects are required to read 50 irregular words aloud, and, on the basis of the number of errors made in pronunciation a reliable estimate of WAIS-R IQ can be calculated (Willshire et al. 1991).

\section{Social Behavior}

Social behavior was evaluated using the Scale for Interpersonal Behavior (SIB). The SIB has been well validated in the general population (U.S., France, The Netherlands) as well as in individuals with social phobia, psychiatric outpatients and -inpatients (Arrindell et al. 2001; Arrindell et al. 1984; Bouvard et al. 1999). Moreover, it has good psychometric properties, such as high test-retest reliability, good internal consistency and good discriminative validity (Arrindell 1985). Besides an overall measure of frequency of participation in social interactions and distress during social interactions, there are four factorially-derived subscales: (I) Display of negative feelings (negative assertion), such as refusing a request or standing up for one's rights in a public situation, (II) Expression of and dealing with personal limitations, such as ability to deal with criticism or requesting attention/ help, (III) Initiating assertiveness, such as starting a conversation with strangers or expressing one's own opinion and (IV) Praising others and the ability to deal with compliments/praise of others (positive assertion), such as giving and receiving compliments. Scores that are obtained with the SIB represent mean item-scores for each dimension of social behavior, on a scale from one (high frequency or low distress) to five (low frequency or high distress).

\section{Autism Traits}

The Autism Spectrum Quotient (AQ) (Baron-Cohen et al. 2001) is a self-administered questionnaire for adults that assesses the degree to which any individual adult of normal intelligence might have features of the core autistic phenotype. It has good test-retest reliability and good discriminative validity for Asperger syndrome at a cut-off score of 26 in a clinical population (Woodbury-Smith et al. 2005). Also, it has good discriminative validity for high functioning autism/Asperger syndrome in the general population using a cut-off score of 32 (Baron-Cohen et al. 2001). Scores on the AQ have shown to be normally distributed in the general population. Five subscales cover personality traits associated with the autistic spectrum; social skills, communication, imagination, attention to detail, and attention switching.

\section{Results}

Intellectual Ability

Mean score on the Raven's Advanced Progressive Matrices was not significantly different between the groups $(F(2.72)=1.3, p=0.27)$ as indicated by an ANOVA. Post-hoc tests also showed no significant differences between XXY men and the control groups $(p=0.18$ and $p=0.16$ ). On the NART, mean score of the Klinefelter men did not significantly differ from the control groups $(F(2,72)=0.7, p=0.48)$. Post-hoc tests also showed no significant differences between XXY men and the control groups $(p=0.46$ and $p=0.58)$. Mean scores are presented in Table 1.

Social Behavior

\section{Distress During Social Interactions}

Overall distress during social interactions was significantly higher in the XXY group as compared to men from the general population. Mean score in the XXY group was 2.2 ( $S D$ 0.67) and in the control group 1.6 (SD 0.49), which was significantly different $(F(1,52)=13.2, p=0.001)$. To compare, the mean score in psychiatric out-patients $(N=253)$ is 2.5 and in individuals with social phobia $(N=119)$ it is 2.8 (Arrindell et al. 1984). In the XXY group significantly higher scores, indicating more distress, were observed for the subscales 'negative assertion' $(F(1,52)=13.9, \quad p<0.001), \quad$ 'personal limitations' $(F(1,52)=12.1, p=0.001)$ and 'initiation assertiveness' $(F(1,52)=20.5, p<0.001)$. Mean distress scores in each dimension of social behavior are presented in Fig. 1.

Frequency of Engagement in Social Interactions

Although overall frequency of engagement in social behavior was not significantly different $(F(1,53)=1.6$,

Table 1 Characteristics of the XXY group and two control groups

\begin{tabular}{lccr}
\hline & XXY group & $\begin{array}{l}\text { Control } \\
\text { group I }\end{array}$ & $\begin{array}{l}\text { Control } \\
\text { group II }\end{array}$ \\
\hline Age & $41.3(10.0)$ & $39.2(13.1)$ & $35.7(8.5)$ \\
$\begin{array}{c}\text { Raven's Matrices } \\
\text { (estimate IQ) }\end{array}$ & $105.2(9.1)$ & $109.4(8.8)$ & $109.6(5.3)$ \\
$\begin{array}{c}\text { NART (estimate } \\
\text { verbal IQ) }\end{array}$ & $108.6(13.5)$ & $110.0(5.3)$ & $107.1(7.8)$ \\
\hline
\end{tabular}

There were no significant differences between the three groups in age, performance on Raven's matrices and the NART, as indicated by ANOVA and subsequent post-hoc tests 


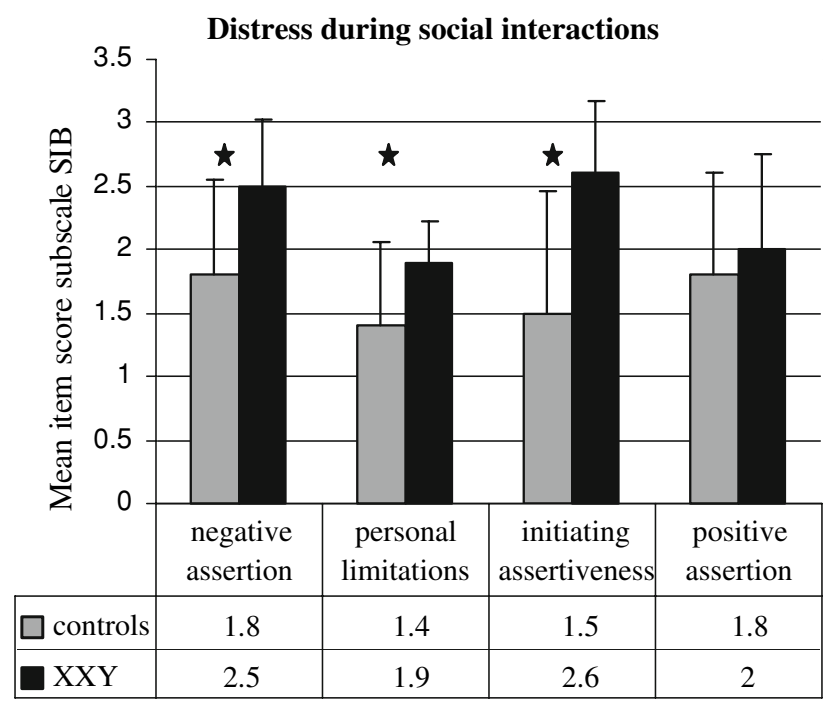

Fig. 1 Self reported distress in XXY men and men from the general population during social interactions in four domains of social behavior: (I) Display of negative feelings (negative assertion), (II) Expression of and dealing with personal limitations, (III) Initiating assertiveness and (IV) Praising others and the ability to deal with compliments/praise of others (positive assertion). * Significantly different at $p \leq 0.001$

$p=0.21)$ between $\mathrm{XXY}$ men (3.2, SD 0.6) and control men (3.1, SD 0.6), the XXY group reported to less frequently display negative assertion, such as refusing a request or standing up for one's rights in a public situation. Mean frequency score in this domain of social behavior was 2.9 ( $S D$ 0.66) in the XXY group and $3.5(S D 1.1)$ in the control group, which was significantly different $(F(1,52)=6.2, p=0.01)$. To compare, the mean score for the subscale negative assertion in psychiatric out-patients $(N=253)$ is 2.9 and in individuals with social phobia $(N=119)$ it is 2.4 (Arrindell et al. 1984). Mean frequency score in each dimension of social behavior is presented in Fig. 2.

\section{Autism Traits}

Mean total AQ score and all subscales separately were significantly higher in Klinefelter men as compared to controls. Total score in the XXY group was 23.8 (SD 6.6) and in the control group $11.0(S D 5.1), F(1,57)=57.8$, $p<0.001)$. In the XXY group, $48 \%(N=15)$ had a total AQ score above the cut-off score for Asperger syndrome in an adult clinical population (i.e. $\geq 26$ ) (Woodbury-Smith et al. 2005). Of these, 6.5\% $(N=2)$ had a total AQ score above the cut-off score for high functioning autism/Asperger syndrome in the general population (i.e. $\geq 32$ ) (Baron-Cohen et al. 2001). See Fig. 3 for the distribution of scores on the autism questionnaire in the Klinefelter group and the control group.

\section{Frequency of participation in social interactions}

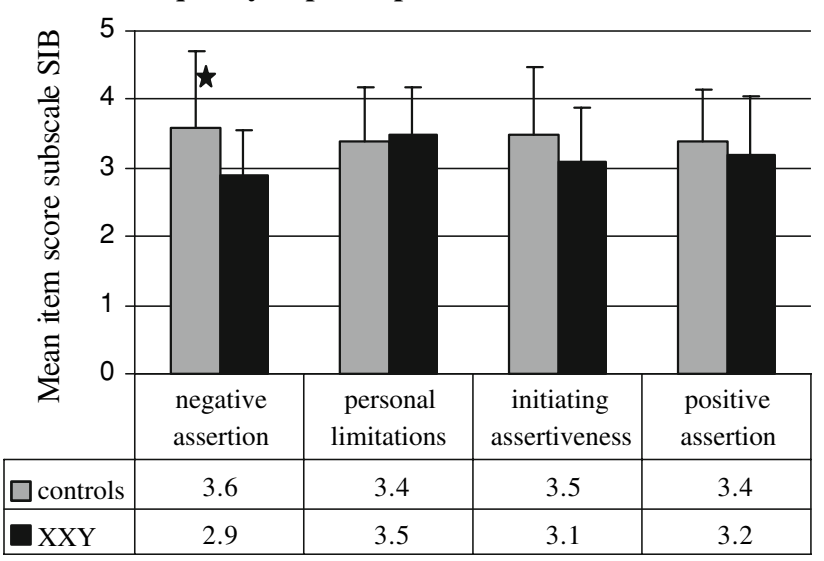

Fig. 2 Self reported frequency of participationsocial interactions in XXY men and men from the general population in four domains of social behavior: (I) Display of negative feelings (negative assertion), (II) Expression of and dealing with personal limitations, (III) Initiating assertiveness and (IV) Praising others and the ability to deal with compliments/praise of others (positive assertion). * Significantly different at $p \leq 0.01$

As compared to men from the general population, XXY men displayed more autism traits in all domains; social skills $(F(1,57)=32.3, \quad p<0.001), \quad$ attention switching $(F(1,57)=38.9, p<0.001)$, attention to detail $(F(1,57)=$ 8.3, $\quad p=0.006), \quad$ communication $\quad(F(1,57)=19.6$, $p<0.001)$ and imagination $(F(1,57)=12.7, p=0.001)$. Effect sizes as expressed in cohen's d were 2.2 for total AQ score, 1.85 for social skills, 1.96 for attention switching, 0.89 for attention to detail, 1.34 for communication and 1.05 for imagination. See Fig. 4 for mean scores and $S D$ 's on the five subscales of the AQ.

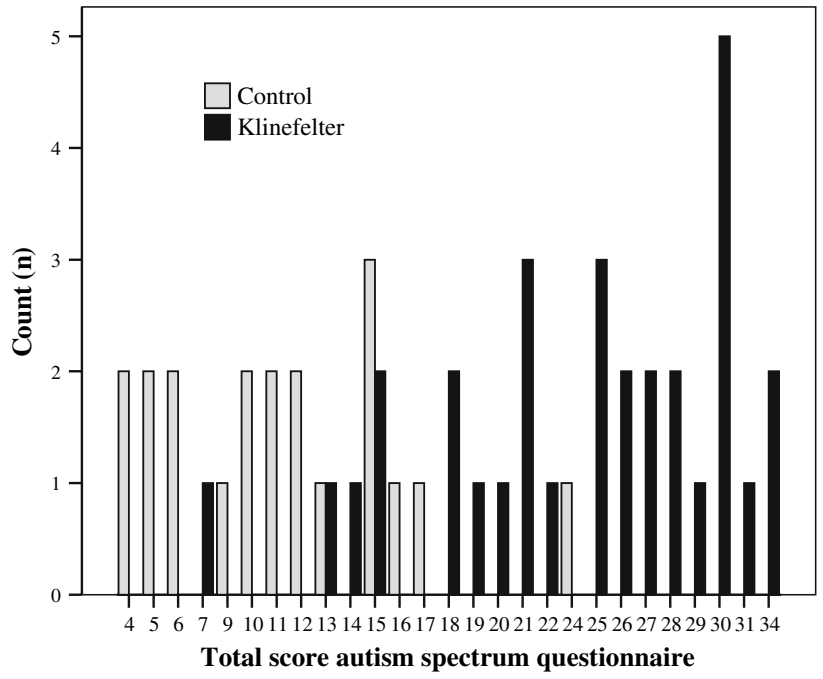

Fig. 3 Frequency distribution of total scores on the Autism Spectrum Questionnaire in the XXY group and control group 


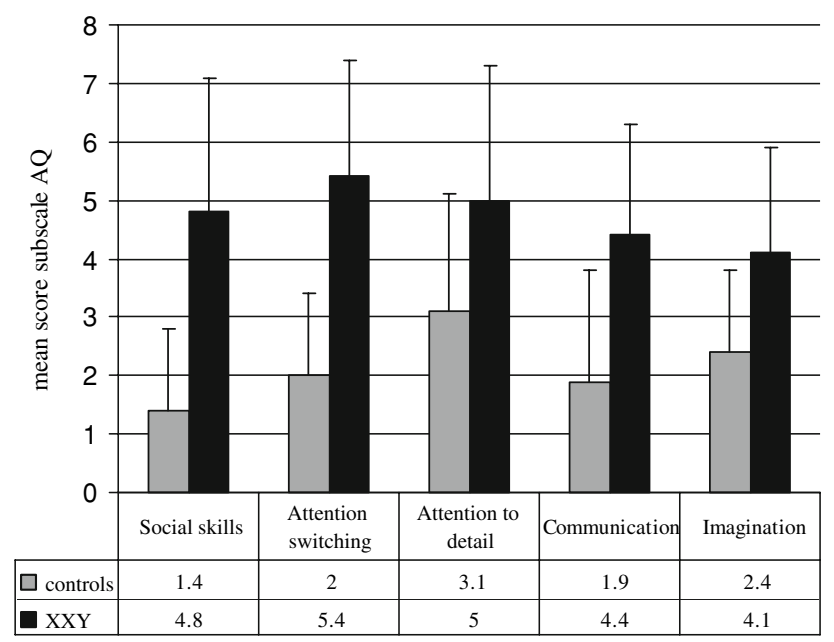

Fig. 4 Levels of autism traits in XXY men and men from the general population as measured with the Autism Spectrum Questionnaire. Scores in all individual dimensions were significantly higher in XXY men

Correlations Between Autism Traits and Social Abilities

In the Klinefelter group there was high positive correlation between total score on the autism questionnaire and total score for frequency of participation in social interactions $(r=.61, p<0.001)$. Similarly, a significant negative association was observed between total score on the autism questionnaire and total score for distress during social interactions $(r=-.61, p<0.001)$. These correlations indicate that in the XXY group more autistic traits are associated with less frequent participation in social interactions and more distress during social interactions. All correlations were corrected for multiple comparisons. Correlations were not calculated for the control men, as two different control groups were included in the study.

\section{Discussion}

The aim of this study was to assess social difficulties in adult men with Klinefelter syndrome and explore the extend to which social disabilities reflect increased levels of features that belong to the autism phenotype. Our main findings were that compared to men from the general population, men with Klinefelter syndrome reported more distress during specific social situations and were characterized by increased levels of autistic features across all dimensions of the autism phenotype.

In the Klinefelter group, increased levels of distress during social interactions were observed in various domains of social behavior, namely: expressing of negative emotions to others, expressing and dealing with personal limitations and initiating contact with others. Although overall frequency of participating in social interactions in $\mathrm{XXY}$ men was not different from men from the general population, significant differences in specific domains of social behavior were observed. XXY men reported to less often engage in social behavior dealing with expression of negative emotions, such as refusing a request or standing up for one's rights in a public situation.

Our findings of difficulties in coping with social situations in XXY men, especially high levels of distress during social interactions, are consistent with reports of social anxiety, social withdrawal and shyness in individuals with the XXY karyotype (Bender et al. 1999; Ratcliffe 1999). Difficulties in social adjustment have primarily been reported for children or adolescents with Klinefelter syndrome. Our data suggest that social difficulties may persist into adulthood, with social distress more prominent than a general reduction in engagement in social interactions. It has been proposed that social difficulties may arise as a consequence of language based learning difficulties (Geschwind et al. 2000), social cognitive impairments (Van Rijn et al. 2006) and verbal disabilities (Rovet et al. 1996) in Klinefelter syndrome.

The high levels of autism traits in XXY men suggest that Klinefelter syndrome may be associated with an increased genetic vulnerability for autistic features. Interestingly, our finding of high rates of autistic traits across all dimensions of the autism phenotype suggest that vulnerability for autistic features in Klinefelter syndrome may not be restricted to impairments in social behavior and communication, but may extend to other aspects of the phenotype as well. Although this observation suggests that XXY men may display the specific combination of various individual traits that are all part of the autism phenotype, some of the traits and symptoms of autism are not specific for the autism phenotype, but may also be seen in individuals with other psychiatric disorders. Therefore, it is possible that men with Klinefelter may not only have an increased vulnerability for autism, but also for other psychiatric disorders.

The significance of the present findings is illustrated by the observation that on the autism questionnaire 15 (48\%) of the XXY men scored above the cut-off for Asperger syndrome in a clinical population and $2(6 \%)$ of the XXY men had a score above the cut-off for high functioning autism/Asperger syndrome in the general population. In the Klinefelter group, higher levels of autism traits were associated with more distress during social interactions and less frequent engagement in social interactions. Interestingly, social difficulties and autistic features in XXY men were observed in the face of spared intellectual abilities. In the XXY group, verbal- and performal-intelligence as measured with the WAIS was within the normal range and performance of the XXY group on Raven's matrices and 
the NART did not significantly differ from control men. The findings of relatively spared intellectual functioning in the XXY group underscore the particular significance of the results with regard to social difficulties and high levels of autistic traits.

Our findings fit with the concept of a 'broad phenotype' of autism, which refers to the mild autistic-like features that are seen in individuals that are genetically related to an individual with autism (Bailey et al. 1998; Bishop et al. 2004). Using the same measure for autism traits (the AQ), increased levels of autism traits have also been found in biological relatives of subject with autism. In a study by Bishop et al. (2004), parents of individuals with autism had significantly higher scores as compared to control parents on the subscales 'social skills' and 'communication'. Mean score for 'social skills' in the group of parents of individuals with autism was 3.0, whereas in our study this was 4.8 for the XXY group. Similarly, mean score for 'communication' in the group of parents of individuals with autism was 2.75 , whereas in our study this was 4.4 for the XXY group. Although it has been suggested that the typical clinical phenotype of autism as seen in subjects with the disorder and the broader subclinical phenotype of autism as seen in biological relatives may share a genetic origin (Rutter 2000), the degree to which the mild autistic-like phenotype in men with Klinefelter syndrome and the broad phenotype of autism share a common genetic remains as yet unclear. However, because Klinefelter syndrome is defined by an $\mathrm{X}$ chromosomal abnormality $(47, \mathrm{XXY})$ we may speculate that the $X$ chromosome might be one of many genetic factors that play a role in the etiology of autism-like behaviors. Support for this hypothesis is derived from studies in Turner syndrome, another $\mathrm{X}$ chromosomal disorder characterized by a partial or complete absence of one of the $\mathrm{X}$ chromosomes in females $(45, \mathrm{XO})$. Turner females also display difficulties in the social domain and the estimated risk of autism spectrum disorders is much higher as compared to women from the general population (Creswell and Skuse 1999; Mazzocco et al. 1998; McCauley and Sybert 2006; Skuse 2000).

With regard to the exact genetic mechanisms that may underlie the effects of an extra $\mathrm{X}$ chromosome on the social behavioral phenotype, we can merely speculate. Isles et al. (2006) have argued that parental origin of a gene impacts the development of social behavior. The differential expression of a gene depending on the parental origin of the gene is referred to as genomic imprinting. Evidence for $\mathrm{X}$-linked imprinting effects on social behavior and underlying brain development has been reviewed by Davies et al. (2006). Badcock et al. (2006) have also reviewed evidence supporting the importance of genomic imprinting in explaining social behavioral phenotypes, and more specifically the autism phenotype. Their 'imprinted brain theory of autism' poses that an imbalance in brain development driven by genomic imprinting gives rise the autism phenotype.

Important empirical evidence for the role of imprinted genes in explaining the social behavioral phenotype comes from studies on Turner syndrome (X0). Females with the single $\mathrm{X}$ chromosome of maternal origin display more social difficulties than Turner females with the single $\mathrm{X}$ chromosome of paternal origin (Skuse et al. 1997). Unfortunately, in the present study subgroups of XXY men with an extra $X$ chromosome of maternal origin versus paternal origin were not of sufficient size for statistical analyses. Although genomic imprinting effects on social behavior have not yet been investigated in Klinefelter syndrome, parental origin of the extra $\mathrm{X}$ chromosome seems to influence at least some aspects of the phenotype of Klinefelter syndrome, such as impaired speech and motor developmental problems (Stemkens et al. 2006). However, other genetic mechanism such as overexpression of genes on the $\mathrm{X}$ chromosome or abnormal $\mathrm{X}$-inactivation may play a role as well (Vawter et al. 2007). Future genetic studies may provide insight into the possible contribution of X-linked genetic mechanisms in explaining the social behavioral and autism-like phenotype in Klinefelter syndrome. Genetic studies investigating the link between $\mathrm{X}$ chromosomal mechanisms and autism features may especially be relevant considering the male preponderance in autism spectrum disorders (Volkmar et al. 1993).

The degree to which the observed behavioral impairments in XXY men represent the effects of testosterone deficits is unclear. Although lower levels of testosterone can be seen after the onset of puberty (Salbenblatt et al. 1985), there are studies showing that prenatal testosterone levels may not differ between individuals with Klinefelter syndrome and male controls (Ratcliffe et al. 1994). Although speculative, support for the hypothesis that at least some aspects of the XXY phenotype may represent the effects of $X$ chromosomal genetic pathology rather than low testosterone levels by itself, comes from individuals with $\mathrm{X}$ chromosomal aneuploidies that are not associated with low testosterone levels. For example, although females with the XXX karyotype are thought to have typical androgen levels, they do display impairments in the language domain and have decreased social adjustment (Bender et al. 1999; Harmon et al. 1998).

Finally, we are aware of some limitations of the present study. As many men with Klinefelter syndrome remain undiagnosed and XXY men in our study were recruited with help from the Dutch Klinefelter Association, our sample may not be completely representative. In spite of this, we believe that the present effect sizes convincingly indicate a relationship between Klinefelter and autism traits, although the possibility that effect sizes might be 
attenuated in a more representative sample cannot be excluded. Also, the finding that the XXY group in our sample was relatively high functioning, as indicated by our measures of intellectual abilities, is in contrast with a bias towards including the more severe cases. Another limitation is that we included two control groups in this study for practical reasons. Therefore, we were not able to calculate correlations between autism traits and social abilities in the control sample. Furthermore, the use of self-report measures might have biased the degree of social disabilities in Klinefelter syndrome. However, studies showing that XXY men tend to overrate, rather than underrate, their own social adjustment (Bender et al. 1999) suggest that our findings might rather be an underestimation than overestimation of social disabilities in Klinefelter syndrome.

Taken together, as compared to men from the general population, XXY men reported increased levels of distress during various types of social interactions and less engagement in those aspects of social behavior that deal with display of negative emotions. Interestingly, we observed considerably increased levels of autistic traits across all dimensions of the autism phenotype in XXY men. The observation that increased levels of autism traits were not only found in the subscales dealing with social skills and communication, but in all subscales of the autism questionnaire, call for a more thorough clinical investigation of vulnerability to autism spectrum pathology in Klinefelter syndrome in a larger and more representative sample in epidemiological terms. Although our findings require replication, Klinefelter syndrome might prove to serve as a useful model for studying a role of the $\mathrm{X}$ chromosome in social behavioral dysfunction and autism-like behavior.

Acknowledgements Sophie van Rijn and Andre Aleman were supported by a 'Vernieuwingsimpuls' grant (no 016.026.027) from the Dutch Orgnaization for Scientific Research (NWO).

Open Access This article is distributed under the terms of the Creative Commons Attribution Noncommercial License which permits any noncommercial use, distribution, and reproduction in any medium, provided the original author(s) and source are credited.

\section{References}

Arrindell, W. A., Bridges, K. R., van der Ende, J., St. Lawrence, J. S., Gray-Shellberg, L., Harnish, R., et al. (2001). Normative studies with the scale for interpersonal behaviour (sib): 2. Us students: A cross-cultural comparison with dutch data. Behaviour Research and Therapy, 39(12), 1461-1479.

Arrindell, W. A., de Groot, P. M., \& Walburg, J. A. (1984). [the scale for interpersonal behavior; manual part 1]. Lisse, the Netherlands: Swets \& Zeitlinger.

Arrindell, W. A., \& Van der Ende, J. (1985). Cross-sample invariance of the structure of self-reported distress and difficulty in assertiveness: Experiences with the scale for interpersonal behaviour. Advances in Behaviour Research and Therapy, 7, 205-243.

Badcock, C., \& Crespi, B. (2006). Imbalanced genomic imprinting in brain development: An evolutionary basis for the aetiology of autism. Journal of Evolutionary Biology, 19(4), 1007-1032.

Bailey, A., Palferman, S., Heavey, L., \& Le Couteur, A. (1998). Autism: The phenotype in relatives. Journal of Autism and Developmental Disorders, 28(5), 369-392.

Baron-Cohen, S., Wheelwright, S., Skinner, R., Martin, J., \& Clubley, E. (2001). The autism-spectrum quotient (aq): Evidence from asperger syndrome/high-functioning autism, males and females, scientists and mathematicians. Journal of Autism and Developmental Disorders, 31(1), 5-17.

Bender, B. G., Harmon, R. J., Linden, M. G., Bucher-Bartelson, B., \& Robinson, A. (1999). Psychosocial competence of unselected young adults with sex chromosome abnormalities. American Journal of Medical Genetics-Neuropsychiatric Genetics, 88(2), 200-206.

Bishop, D. V. M., Maybery, M., Maley, A., Wong, D., Hill, W., \& Hallmayer, J. (2004). Using self-report to identify the broad phenotype in parents of children with autistic spectrum disorders: A study using the autism-spectrum quotient. Journal of Child Psychology and Psychiatry and Allied Disciplines, 45(8), 1431-1436.

Boone, K. B., Swerdloff, R. S., Miller, B. L., Geschwind, D. H., Razani, J., Lee, A., et al. (2001). Neuropsychological profiles of adults with klinefelter syndrome. Journal of the International Neuropsychological Society, 7(4), 446-456.

Bouvard, M., Arrindell, W. A., Guerin, J., Bouchard, C., Rion, A. C., Ducottet, E., et al. (1999). Psychometric appraisal of the scale for interpersonal behavior (sib) in france. Behaviour Research and Therapy, 37(8), 741-762.

Constantino, J. N., \& Todd, R. D. (2003). Autistic traits in the general population: A twin study. Archives of General Psychiatry, 60(5), 524-530.

Creswell, C. S., \& Skuse, D. H. (1999). Autism in association with turner syndrome: Genetic implications for male vulnerability to pervasive developmental disorders. Neurocase, 5(6), 511-518.

Davies, W., Isles, A. R., Burgoyne, P. S., \& Wilkinson, L. S. (2006). $\mathrm{X}$-linked imprinting: Effects on brain and behaviour. Bioessays: News and Reviews in Molecular, Cellular and Developmental Biology, 28(1), 35-44.

Geschwind, D. H., Boone, K. B., Miller, B. L., \& Swerdloff, R. S. (2000). Neurobehavioral phenotype of klinefelter syndrome. Mental Retardation and Developmental Disabilities Research Reviews, 6(2), 107-116.

Geschwind, D. H., \& Dykens, E. (2004). Neurobehavioral and psychosocial issues in klinefelter syndrome. Learning Disabilities Research \& Practice, 19(3), 166-173.

Harmon, R. J., Bender, B. G., Linden, M. G., \& Robinson, A. (1998). Transition from adolescence to early adulthood: Adaptation and psychiatric status of women with 47, XXX. Journal of the American Academy of Child and Adolescent Psychiatry, 37(3), 286-291.

Isles, A. R., Davies, W., \& Wilkinson, L. S. (2006). Genomic imprinting and the social brain. Philosophical Transactions of the Royal Society of London Series B Biological Sciences, 361(1476), 2229-2237.

Jha, P., Sheth, D., \& Ghaziuddin, M. (2007). Autism spectrum disorder and klinefelter syndrome. European Child and Adolescent Psychiatry, 16(5), 305-308.

Kielinen, M., Rantala, H., Timonen, E., Linna, S. L., \& Moilanen, I. (2004). Associated medical disorders and disabilities in children with autistic disorder: A population-based study. Autism, 8(1), 49-60. 
Konstantareas, M. M., \& Homatidis, S. (1999). Chromosomal abnormalities in a series of children with autistic disorder. Journal of Autism and Developmental Disorders, 29(4), 275-285.

Lanfranco, F., Kamischke, A., Zitzmann, M., \& Nieschlag, P. E. (2004). Klinefelter's syndrome. The Lancet, 364(9430), 273-283.

Lezak, M. D. (1995). Neuropsychological assessment (3rd Ed.). New York: Oxford University Press.

Mazzocco, M. M. M., Baumgardner, T., Freund, L. S., \& Reiss, A. L. (1998). Social functioning among girls with fragile $\mathrm{x}$ or turner syndrome and their sisters. Journal of Autism and Developmental Disorders, 28(6), 509-517.

McCauley, E., \& Sybert, V. (2006). Social and behavioral development of girls and women with turner syndrome. International Congress Series, 1298, 93-99.

Merhar, S., \& Manning-Courtney, P. (2007). Two boys with 47, xxy and autism. Journal of Autism and Developmental Disorders, 37(5), 840-846.

Nelson, H. E. (1982). National adult reading test (nart), manual. Windsor: NFER-Nelson.

Nielsen, J., Johnsen, S. G., \& Sorensen, K. (1980). Follow-up 10 years later of 34 klinefelter males with karyotype 47,xxy and 16 hypogonadal males with karyotype 46,xy. Psychological Medicine, 10(2), 345-352.

Ratcliffe, S. (1999). Long-term outcome in children of sex chromosome abnormalities. Archives of Disease in Childhood, 80(2), 192-195.

Ratcliffe, S. G., Read, G., Pan, H., Fear, C., Lindenbaum, R., \& Crossley, J. (1994). Prenatal testosterone levels in xxy and xyy males. Hormone Research, 42(3), 106-109.

Raven, J. C., Raven, J., \& Court, J. H. (1993). Manual for raven's progressive matrices and vocabulary scales. Oxford: Oxford Psychologist Press.

Rovet, J., Netley, C., Keenan, M., Bailey, J., \& Stewart, D. (1996). The psychoeducational profile of boys with klinefelter syndrome. Journal of Learning Disabilities, 29(2), 193-196.

Rutter, M. (2000). Genetic studies of autism: From the 1970s into the millennium. Journal of Abnormal Child Psychology, 28(1), 314.

Salbenblatt, J. A., Bender, B. G., \& Puck, M. H. (1985). Pituitarygonadal function in klinefelter syndrome before and during puberty. Pediatric Research, 19(1), 82-86.

Schmand, B., Bakker, D., Saan, R., \& Louman, J. (1991). [the dutch reading test for adults: A measure of premorbid intelligence level]. Tijdschrift voor Gerontologie en Geriatrie, 22(1), 15-19.
Sheehan, D. V., Lecrubier, Y., Sheehan, K. H., Amorim, P., Janavs, J., Weiller, E., et al. (1998). The mini-international neuropsychiatric interview (m.I.N.I.): The development and validation of a structured diagnostic psychiatric interview for dsm-iv and icd10. Journal of Clinical Psychiatry, 59(Suppl 20), 22-33;quiz $34-57$.

Simm, P. J., \& Zacharin, M. R. (2006). The psychosocial impact of klinefelter syndrome-a 10 year review. Journal of Pediatric Endocrinology and Metabolism, 19(4), 499-505.

Skuse, D. H. (2000). Imprinting, the x-chromosome, and the male brain: Explaining sex differences in the liability to autism. Pediatric Research, 47(1), 9-16.

Skuse, D. H., James, R. S., Bishop, D. V., Coppin, B., Dalton, P., Aamodt Leeper, G., et al. (1997). Evidence from turner's syndrome of an imprinted $x$-linked locus affecting cognitive function. Nature, 387(6634), 705-708.

Spiker, D., Lotspeich, L. J., Dimiceli, S., Myers, R. M., \& Risch, N. (2002). Behavioral phenotypic variation in autism multiplex families: Evidence for a continuous severity gradient. American Journal of Medical Genetics - Neuropsychiatric Genetics, 114(2), 129-136.

Stemkens, D., Roza, T., Verrij, L., Swaab, H., van Werkhoven, M. K., Alizadeh, B. Z., et al. (2006). Is there an influence of $\mathrm{x}$ chromosomal imprinting on the phenotype in klinefelter syndrome? A clinical and molecular genetic study of 61 cases. Clinical Genetics, 70(1), 43-48.

Van Rijn, S., Swaab, H., Aleman, A., \& Kahn, R. S. (2006). X chromosomal effects on social cognitive processing and emotion regulation: A study with klinefelter men $(47, \mathrm{xxy})$. Schizophrenia Research, 84(2-3), 194-203.

Vawter, M. P., Harvey, P. D., \& DeLisi, L. E. (2007). Dysregulation of $\mathrm{x}$-linked gene expression in klinefelter's syndrome and association with verbal cognition. American Journal of Medical Genetics Part B: Neuropsychiatric Genetics, 144(6), 728-734.

Volkmar, F. R., Szatmari, P., \& Sparrow, S. S. (1993). Sex differences in pervasive developmental disorders. Journal of Autism and Developmental Disorders, V23(4), 579-591.

Willshire, D., Kinsella, G., \& Prior, M. (1991). Estimating wais-r iq from the national adult reading test - a cross-validation. Journal of Clinical and Experimental Neuropsychology, 13(2), 204-216.

Woodbury-Smith, M. R., Robinson, J., Wheelwright, S., \& BaronCohen, S. (2005). Screening adults for asperger syndrome using the aq: A preliminary study of its diagnostic validity in clinical practice. Journal of Autism and Developmental Disorders, V35(3), 331-335. 